\title{
Risk Factors Contributing in Increased Susceptibility and Severity of COVID-19 Infection during Pregnancy
}

\author{
Imad R. Musa (1) \\ Royal Commission Hospital, Jubail Industrial City, KSA \\ Email: irthesudanese@hotmail.com
}

How to cite this paper: Musa, I.R. (2020) Risk Factors Contributing in Increased Susceptibility and Severity of COVID-19 Infection during Pregnancy. Open Journal of Obstetrics and Gynecology, 10, 1197-1215. https://doi.org/10.4236/ojog.2020.1090113

Received: August 24, 2020

Accepted: September 14, 2020

Published: September 17, 2020

Copyright $\odot 2020$ by author(s) and Scientific Research Publishing Inc. This work is licensed under the Creative Commons Attribution International License (CC BY 4.0).

http://creativecommons.org/licenses/by/4.0/

\section{(c) (i) Open Access}

\begin{abstract}
The corona virus disease 2019 (COVID-19) pandemic has spread globally and pregnant women are considerably prone to COVID-19 infection with increased maternal and perinatal complications. Aim: This study aims to explore the risk factors that contribute to susceptibility and severity of COVID-19 infection among pregnant women. Method: A literature search of articles relating to COVID-19 infection during pregnancy, was conducted, using PubMed, Scopus and Google scholar engine. Result: A total of 168 articles were initially identified. Eighty four papers were excluded for failing to address the aim of the study. After screening titles and abstracts, eighty four full-text articles were retrieved for eligibility analysis. Nineteen studies addressed the susceptibility related to pregnancy, twenty-two studies evaluated the associated comorbidities, nineteen focused on immune system, thirty-six articles concentrated on the risk of coagulopathy and eleven addressed more than one risk factor. Conclusion: Pregnancy, associated comorbidities, modulated immune response during pregnancy and risk of coagulopathy are considerable risk factors contributing to COVID-19 pathogenesis among pregnant women and may predict the outcome.
\end{abstract}

\section{Keywords}

Pregnancy, Corona Virus, COVID-19, SARS-CoV-2

\section{Introduction}

COVID-19 or novel coronavirus (2019-nCoV) infection was declared as pandemic by the World Health Organization on March 11, 2020 and resulted in marked increase in morbidity and fatality globally. Recent data released on $2^{\text {nd }}$ of 
May 2020, have shown 3,402,160 of confirmed cases worldwide, deaths 239,623 individuals, recovered 1,083,943 subjects, mild cases 2,027,228 (98\%) and 51,366 (2\%) patients were seriously or critically ill [1]. Likewise, a weekly report of morbidity and mortality from the United States of America, on March 28, 2020, confirmed a total of 122,653 of cases with COVID-19 infection; $2 \%$ of these cases were found to be pregnant and about 3.8\% were smokers. Approximately one third of these patients (smoking and pregnancy) (2692, 37.6\%), had at least one underlying chronic medical condition or risk factor: diabetes mellitus (DM) (10.9\%), chronic lung disease (9.2\%), and cardiovascular disease (9.0\%) [2]. The most common symptoms at presentation were fever (75\%) and cough (73\%) [3]. Higher percentage of DM and hypertension may be linked to the global increase in the prevalence, including some developing countries [4] [5] [6] [7]. Furthermore, the presence of one or more comorbidities, would be reflected in severity of the disease and a higher percentage of hospital admission: in intensive care unit (ICU) (78\%) and non-ICU hospitalizations (71\%) [2]. On the other hand, only (27\%) COVID-19 patients who did not require hospitalization, were found to have at least one underlying medical condition [2]. Some clinical data, showed most cases presented in the $3^{\text {rd }}$ trimester that hires potential risk for complications compared to few numbers of cases who presented in earlier gestational age with favorable outcome [3] [8]. The rate of Cesarean section was considered very high in this group of patients $(92 \%$ - 93\%) compared to recorded successful vaginal delivery [3] [8]. The case fatality rate has been estimated at around 3\% for the novel coronavirus and it was too early to be able to put a percentage on the mortality rate because fatality rate can change as a virus can mutate [9] [10]. A recently published study that recruited 118 pregnant women with confirmed COVID-19 infection, found (92\%) had mild disease, (8\%) had severe disease (hypoxemia), and only one case required noninvasive mechanical ventilation. Interestingly, (94\%) of them had been discharged, including all women with severe or critical disease without reported fatality [8]. Moreover, they reported only $3 \%$ of pregnant women with confirmed SARS-CoV-2 infection who required maternal intensive care admission and successfully recovered with no confirmed fatalities [8]. Similarly, a study from China, reported a favorable risk of severe COVID-19 disease in (8\%) of pregnant women compared with the risk in the general population (15.7\%) [11]. One study showed mild presentation of the disease in 368 (95.6\%) of pregnant women, severe course in (3.6\%) and critical in $(0.8 \%)$. Interestingly, only one patient died from seventeen (4.4\%) women who required management in an intensive care unit (ICU) [12]. In contrast, the case fatality rate for SARS and MERS was $10 \%$ and $37 \%$ respectively [13]. Despite comparatively lower rate of fatality in SARS-CoV infection (10\%), a relatively higher rate was registered among pregnant women (25\%) [1] [14]. In a systematic review evaluating 385 pregnant women with COVID-19 infection, the perinatal complications were obtained, including preterm birth (15.2\%) newborns, Low birth weight (7.8\%) newborns, intrauterine fetal distress $(7.8 \%)$ 
newborns and confirmed vertical transmission in (1.2\%) of newborns [12]. In case series study, assessing nine pregnant women with severe COVID-19 disease, a considerable higher death rate was reported in seven cases [15]. For potential increase in the vulnerability of pregnant women and few papers addressing this issue during the current pandemic, I conducted this study to evaluate the possible risk factors that prone pregnant women to COVID-19 infection.

\section{Method}

A literature search of studies focusing COVID-19 infection during pregnancy, was conducted without frame time limit, using PubMed, Scopus and Google scholar, with the key the words: "pregnancy", "coronavirus", "COVID-19", "SARS-CoV-2", "susceptIbility", "risk factors", "complications", "comorbidities" and "outcome". The Preferred Reporting Items for Systematic Review and Meta-Analysis (PRISMA) guidelines were adopted for selection of articles as illustrated in Figure 1 [16]. The electronic database search generated 168 studies.

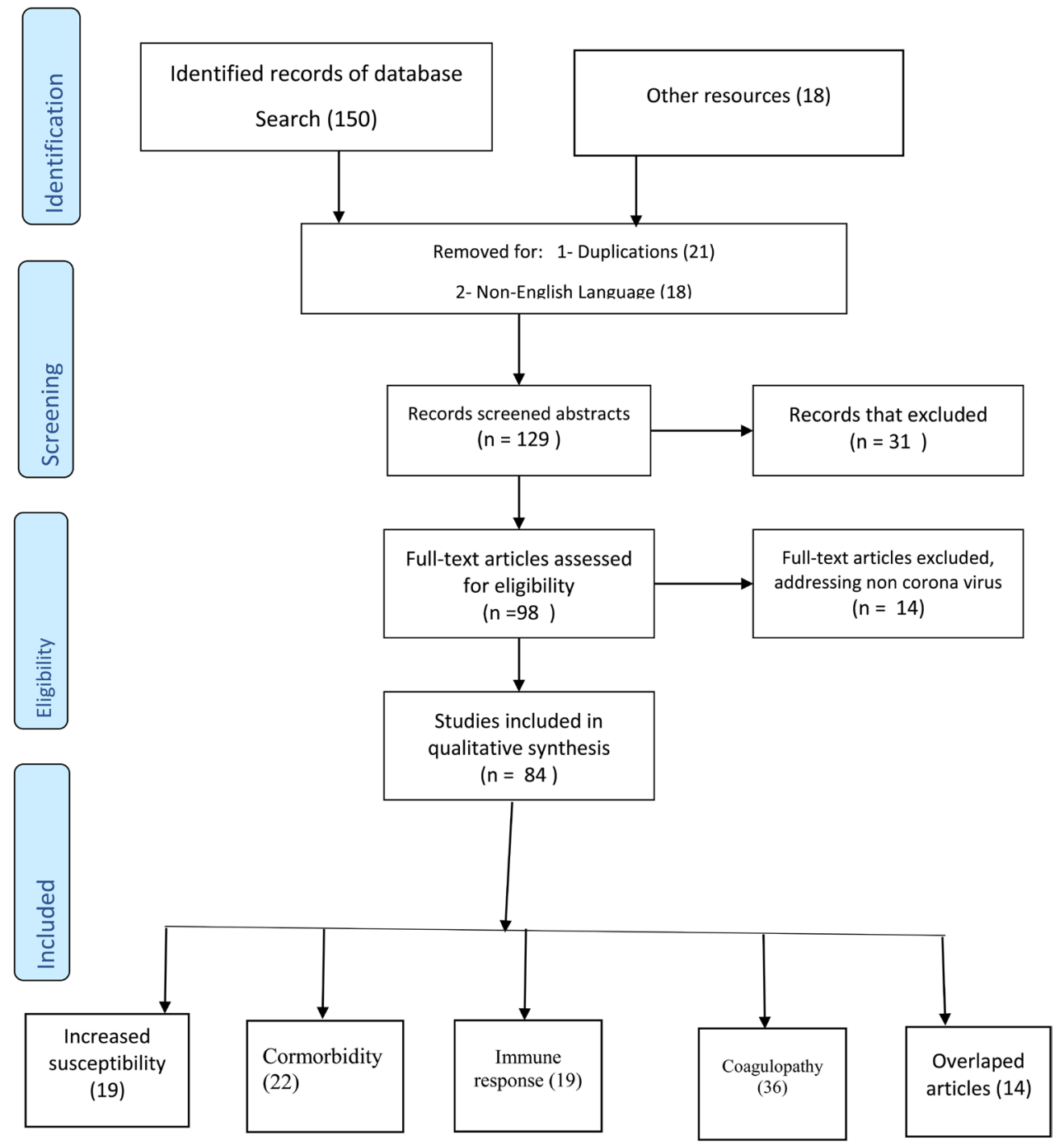

Figure 1. Flow chart of the study selection. 
Eighty four studies were excluded for not fulfilling the aim of the study, duplication, lacking proper citation, and language issue. Titles and abstracts were evaluated to identify eligibility for full screening. Studies that employed acceptable quantitative and/or qualitative methods, including randomized controlled trials, observational studies (such as cross-sectional, experimental, and interventional studies), review articles, editorials, reports, ideas, letters to the editor and opinions were included. All studies focusing on the pathogenesis of COVID-19 among pregnant women, risk factors related pregnancy, effects of associated comorbidities, immune response, medications influence and risk of coagulopathy associated with COVID-19 were eligible for inclusion. Once all relevant articles had been determined, full-text manuscripts were retrieved for assessment. The clinical opinions were critically appraised by using the checklist ( 7 elements) that were recommended by McArthur et al. (2015) that yielded eighty four relevant articles [17]. Then the studies were grouped according to the primary aims, risk related to pregnancy, associated comorbidities, immune response and risk of coagulopathy. This facilitated identification of proper articles that concentrated on specific topics and issues relevant to my objectives and enabled the retrieval of information.

\section{Result}

A total of 168 articles were initially identified. Eighty four studies were removed for not addressing the target of the study, duplication, lacking proper citations and language issue. After screening titles and abstracts, eighty four full-text articles were retrieved for eligibility analysis. Nineteen studies addressed the susceptibility related to pregnancy [8] [9] [12] [14] [18]-[32], twenty two studies evaluated the associated comorbidities [11] [19] [31]-[51], nineteen focused on immune system [8] [21] [22] [23] [24] [52]-[65], thirty six article concentrated on the risk of coagulopathy [8] [16] [57] [66]-[97] and fourteen addressed more than one risk factor [8] [9] [11] [12] [14] [18] [19] [21] [22] [23] [24] [25] [32] [57]. The risk factors appear to have a predictor value for increasing susceptibility to COVID-19 infection and worsening the outcome among pregnant women.

\section{Discussion}

Pregnancy has some factors that may potentiate the vulnerability to COVID-19 infection and severity of presentation. From anatomical aspect, the size of the chest cavity is markedly affected by the growing womb during pregnancy, leaving less space for the lungs to expand, especially in the last trimester. This explains why pregnant women often experience difficulty in breathing during mild episodes of chest infection and worsen if they had COVID-19 infection [8] [18] [19]. Similarly, pregnant women are prone to respiratory pathogens and at risk of pneumonia compared with nonpregnant women due to physiological adaptations in pregnancy: airway edema, diaphragmatic elevation, increased oxygen consumption, and pregnancy-related immune-alterations [20]. Thus their to- 
lerance to hypoxia is significantly impaired [20]. Furthermore, gestational rhinitis that affects one-fifth of healthy women in late pregnancy, is estrogen mediated hyperemia of the nasopharynx, leading to marked nasal congestion and rhinorrhea that may mask the coryzal symptoms of COVID-19 infection. This may lead to active viral shedding and increase risk of community transmission in low suspicious judgement for COVID-19 infection, besides resulting in late presentation of the disease [19] [21]. Additionally, they are exposed to higher risk of other respiratory pathogens [19]. The circulating higher levels of maternal estrogens and progesterone through most of gestational age, are believed to exert immunomodulatory effect to promote safe pregnancy [22] [23]. Progesterone's immune-adaptive response is characterized by promoting Th 2-type responses, increase expression of leukemia inhibitory factor, reducing levels of cytokines (IFN- $\gamma$, TNF- $\alpha$, IL-5, and IL-10) and increasing levels of IL-4 production by $\mathrm{CD} 8^{+} \mathrm{T}$ cells [22] [23]. Likewise, higher levels of prolactin, have stimulatory effects on cell-mediated, humoral immune responsiveness and may extend to include the innate immune effector cells [24]. In fact, SARS-CoV-2 enters the cell via the angiotensin-converting enzyme 2 (ACE2) receptor, which is upregulated in normal pregnancy [25]. For the placenta-related pathology, we will focus our discussion on the temporal expression of ACE2 throughout gestation for possible propagation of SARS-CoV-2 in the placenta in infected women and ensuing consequences [26].

Physiological and mechanical changes in pregnancy increase susceptibility to infections in general, particularly when the cardiorespiratory system is affected, will precipitate rapid progression to respiratory failure in pregnancy [27]. Previous reports demonstrated $27 \%$ fatality among 1350 pregnant women who got the disease during the 1918 influenza pandemic [18]. Similarly, the SARS virus, had general case fatality of $25 \%$ among pregnant women and increased to $50 \%$ of those who required ICU admission [14]. In the $2009 \mathrm{H} 1 \mathrm{~N} 1$ influenza virus outbreak, pregnant women had four times chance to be admitted with increased risk of complications compared with the general population [28]. Similar outcome may be extrapolated for COVID-19 infection among pregnant women in the light of earlier pandemic stage of COVID-19 and being related to coronavirus family. Recently published clinical data linked pregnancy to increased susceptibility to COVID-19 and hired potential risk for severe presentation [21] [29] [30]. The $3^{\text {rd }}$ trimester appears to bring in a higher potential risk to contract the disease $(64 \%-80 \%)$ compared to presentation in earlier gestational age which may favor better prognosis and outcome [8] [9]. Furthermore, the rate of documented cesarean section was very high (92\%) compared to successful normal vaginal delivery (8\%) [8]. Another study documented almost similarly higher rate of cesarean sections (93\%), (61\%) the procedure was indicated of concern about the effects of COVID-19 on the pregnancy and (21\%) were delivered premature [9]. In addition to clear documented perinatal complications related to COVID-19 disease [12]. In contrast, a systematic review reported only $3 \%$ of pregnant women with confirmed SARS-CoV-2 infection required intensive care 
management and no confirmed fatalities were reported [8]. Recently, the outcome of some studies lacked the clear evidence to consider pregnancy as a risk factor for more severe disease in women with COVID-19 [19] [31] [32]. The growing body of evidence as reported in many studies as mentioned above, considered the physiological and anatomical changes during pregnancy as potential risk factors to increase susceptibility to COVID-19 infection, severe presentation, maternal and fetal complications. Thus vigilant and proper earlier management is required to improve the outcome.

Indeed, comorbidities such as diabetes, cardiac failure, or hypertension, have been identified as risk factors for severe COVID-19 infections in nonpregnant adults and also are considered additional risk factors for pregnant women to hire worse prognosis [32]. Among different comorbidities registered, hypertension (3026, 56.6\%), obesity $(1737,41.7 \%)$, and diabetes $(1808,33.8 \%)$ appeared to be the most common medical problems that were associated with COVID-19 infection and might predict severity of the disease [33]. Recently, one study from the United States of America, assessed the comorbidities during this COVID-19 pandemic among pregnant women. Obesity was the most common associated comorbidity (60.5\%) and (41.8\%) had an additional comorbid condition, including mild intermittent bronchial asthma (18.6\%), type 2 diabetes mellitus (7.0\%) and chronic hypertension (7.0\%) [34]. Obese and obese-diabetic state are characterized by chronic and low-grade inflammation that affects different steps of the innate and adaptive immune response [35]. Furthermore, chronically higher leptin (a pro-inflammatory adipokine) and lower adiponectin (an anti-inflammatory adipokine) concentrations were observed among obese subjects [36]. Similarly, reduced physical activity and insulin resistance hinder immune response against microbial agents [37] [38]. Additionally, obese patients are more likely to delay clearance of influenza virus and vulnerable to the emergence of novel and more virulent virus strains as a result of impaired interferons production [39] [40]. Likewise, people with asthma are more likely to have severe outcomes with common cold virus infections than those without it [41], and dramatically worsening is observed in uncontrolled asthma as a result of virus-induced exacerbation [42]. Deficient and delayed innate anti-viral immune responses, besides observed deficiency and delay in lung cell cytokines functions (interferon (IFN)- $\alpha$ [43], IFN- $\beta$ [44] and IFN- $\lambda$ [45] in patients with bronchial asthma [45]. Furthermore, the deficiency of IFN- $\lambda$ is causally linked to increased asthma exacerbation episodes and severity [19]. Based on this evidence, may deduce that bronchial asthma should be considered as a risk factor and predictor for severe outcomes in COVID-19 disease. Additionally, in the largest case series recruiting 44,672 confirmed COVID-19 cases, reported chronic respiratory disease, including bronchial asthma, as the third highest case fatality ratio, after cardiovascular disease and DM [46]. Common comorbidities, DM (7.4\%) and hypertension (15.0\%) were frequently reported in patients with confirmed COVID-19 and predicted the severity of the disease [11]. Similar outcome was obtained regarding the higher rate of comorbidities among infected cases with 
COVID-19 as they were more vulnerable than the general population [47] [48] predicts hospital admission [49] and intensive care management [47]. Recently, one study pointed to the associated comorbidities (hypertension, proteinuria, gestational diabetes mellitus and morbid obesity) and the risk developing pulmonary edema/embolism, from COVID-19 infection during pregnancy [50]. Hence, pregnancy might mask the beneficial effect of the gender as cellular studies revealed attenuation of Angiotensin-converting enzyme 2 expression in females, that supporting the epidemiological observation of male predominance for susceptibility of COVID-19 infections [11] [51]. Based on these evidences, coexistence of comorbidities during pregnancy appears to be an additive risk factor for susceptibility and predictor for severe COVID-19 infection that necessitates proper management to achieve a favorable prognosis.

Pregnancy is considered as a partially immunocompromised state, hence pregnant women are more susceptible to viral or bacterial pneumonia than non-pregnant adults, leading to life-threatening condition during pregnancy [52]. Since SARS-CoV-2 is a novel virus, thus herd immunity is not well developed yet among individuals that, makes everyone susceptible [53]. Likewise, pregnant women are more vulnerable to respiratory pathogens including COVID-19 infection than the general population [53]. The effects of elevated level progesterone and estrogen during pregnancy in promoting Th2-type immune responses favoring adaptive immune response to maintain progression of the pregnancy, was identified in some clinical data [22] [23] besides, the influence of prolactin in innate immunity [24]. This might explain the relative improvement or reduce severity during pregnancy for some $\mathrm{T}$ helper cell type 1-mediated autoimmune diseases (rheumatoid arthritis and multiple sclerosis), and $\mathrm{T}$ helper cell type 2-mediated disorders such as systemic lupus erythematosus [22] [23] [24]. T-helper lymphocytes are the major cytokines producers that regulate immune response and inflammatory process. Th1-type cytokines are basically microbicidal and proinflammatory properties which include interferon-g (IFN-g), interleukin (IL)1a, IL-1b, IL-6, and IL-12 [54]. This is usually balanced naturally by Th2-type cytokines which work as anti-inflammatory substances and comprise IL-4, IL-10, IL-13, and transforming growth factor b [54]. During pregnancy, the bias toward Th2 system dominance and the attenuation in cell-mediated immunity by Th1 cells due to the physiological shift, that favoring fetus protection, leaving the mother vulnerable to the risk of viral infections and other intracellular pathogens [21]. These unique challenges play a potential role in increasing susceptibility to viral infections including SARS-CoV-2. Given that the cytokine profiles in SARS-CoV and SARS-CoV-2 infections in nonpregnant patients, may be extrapolated to account for the differences in disease severity during pregnancy [55]. In fact patients with SARS disease showed preferential activation of Th1 immunity, which is characterized by marked elevation of proinflammatory cytokines (IFNg, IL-1b, IL-6, and IL-12), leading to extensive lung damage and complicates disease presentation [56]. On the other hand, patients with COVID-19 disease, have tendency to activate both Th1 and 
Th2 immune response during the course of the disease [57]. In addition, elevated levels of IL-6, a predominant Th1 cytokine, are associated with a significantly increased risk of mortality in patients with COVID-19 disease [58]. In murine experimental studies of influenza, have documented that pregnancy potentiates influenza-related pathology as a result of defective viral clearance, increased pulmonary cytokines (IL6, IL-1a), and Granulocyte-colony stimulating factor expression. Moreover, prostaglandin and progesterone levels have an influential role in immune response during pregnancy [59]. The study extrapolated that immunological responses to viral pathogens are influenced by the hormonal changes during pregnancy [59]. Hence early adaptive immune responses during COVID-19 infection may predict severity of the disease [60]. In contrast, one study justified the lesser severity of COVID-19 infection among pregnant women compared to that in nonpregnant individuals, due to the physiological transition to Th2 activities, favoring the arm of anti-inflammatory cytokines (IL-4 and IL-10) and other possible unknown immune adaptations [61]. Additionally, lymphocytopenia was reported in considerable number of COVID-19 cases during pregnancy (59\%) and associated with an elevated C-reactive protein concentration $(>10 \mathrm{mg} / \mathrm{L})$ in $(70 \%)$ of cases [8]. Moreover, the innate immune cells, such as Natural killer cells and monocytes, are in particular, protecting the body from viral invasion [62]. This mission is markedly modulated during pregnancy by the adaptive immune responses: down-regulated during pregnancy (decreased numbers of $\mathrm{T}$ and $\mathrm{B}$ cells) hence hindering its antiviral efficacy [62]. Severe COVID-19 infection is related to cytokine-storm, which is characterized by increased plasma concentrations of different cytokines: interleukins 2 (IL2), IL-7, IL-10, tumor necrosis factor $\alpha$ (TNF- $\alpha$ ), interferon- $\gamma$-inducible protein 10 , granulocyte-colony stimulating factor, monocyte chemoattractant protein 1 and macrophage inflammatory protein 1 alpha [57]. Basically, it is triggered by antibody dependent enhancement of SARS-CoV-2 as a result of prior exposure to similar antigenic epitopes with other members of coronaviruses family [63]. Hence, the characteristic immune responses during pregnancy and potential risks of COVID-19 infection induced cytokine-storm hire severe morbidity and predict mortality [53]. Not only pregnant women may be affected during cytokine storm, but fetus may suffer from several associated complications: fetal brain development with a wide range of neuronal dysfunctions and behavioral phenotypes [64]. On the other hand, some studies considered pregnant women are not more susceptible to the majority of infectious diseases, nor they are immune from effects of the majority of autoimmune disorders [22] [23] [24]. Similarly, some authors preferred to refer to pregnancy as a unique immune state that is modulated, but not suppressed [23] [24] [65]. We can conclude that pregnancy is special condition and contracting COVID-19 during pregnancy may complicate the prognosis and outcome.

Pregnancy is physiologically hypercoagulable state, with rising levels of coagulation factors as reflected by $50 \%$ increase in fibrinogen and $\mathrm{D}$-dimers above baseline by the third trimester [66]. The dysfunction of endothelial cells induced 
by infection results in excess thrombin generation and fibrinolysis shutdown, which indicated a hypercoagulable state in patient with infection [67] [68] [69] [70], such as COVID-19 infection that resulted in diffuse endothelial inflammation [71]. In addition, the hypoxia found in severe COVID-19 can stimulate thrombosis through increasing blood viscosity and a hypoxia-inducible transcription factor-dependent signaling pathway [72] [73] [74], as an evidence, occlusion and micro-thrombosis formation in small pulmonary vessels of critical patient with COVID-19, has been reported from a recent lung tissue study [75]. Hence, early initiation of anticoagulant therapy in severe COVID-19 disease was recommended to improve the outcome [76]. It was clearly documented in case series study, disseminated intravascular coagulopathy (DIC) complicated COVID-19 infection in pregnant women [18]. Likewise, the observation of higher D-dimers levels in non-survivors when was compared to survivors of COVID-19 infection [73]. While, previous study, was not promoting the use typical $\mathrm{D}$-dimer rise during gestation as indicator for unfavorable prognosis in pregnancy [66], recent study, justified a significant D-dimer elevation (cutoff; 3-4fold above ULN) as clear indication for hospital admission irrespective of absence of other suggestive symptoms [77]. Upon binding to ACE2, SARS-CoV-2 causes its downregulation, thus lowering angiotensin-(1-7) levels, which can mimic/worsen the vasoconstriction, inflammation, and pro-coagulopathic effects that occur in preeclampsia [25]. Furthermore, severe pneumonia causally related to COVID-19 is frequently associated with coagulopathy and a high of level of D-dimer and is directly linked to poor prognosis [59] [73] [78]. In the light of invalidated sepsis induced coagulopathy (SIC) score during pregnancy, the poor prognostic implication of high D-dimers and beneficial effects of anticoagulation prophylaxis therapy in non-pregnant individuals with COVID-19 infection, prophylactic low-molecular-weight heparin administration may be of paramount value when immediately use in the postpartum period for COVID-19 positive cases [79]. This was strengthened by recent study that assessed the DIC, based on the International Society on Thrombosis and Hemostasis (ISTH) criteria among survivors and non-survivors of COVID-19 infection, which were $0.6 \%$ and $71 \%$ respectively [80]. Increased mortality was observed with high levels of APTT, PT, D-dimer, and fibrin degradation products compared to COVID-19 survivors [69]. Surprisingly, neither APTT nor low fibrinogen was evaluated in a pregnancy series although both being used as elements in DIC classification [79]. On the other hand, data related to other tests lack strong certainty and often conflict [81] [82]. Plausibly there is documented observation that linked maternal COVID-19 infection in third-trimester and rapid maternal deterioration, with progressive coagulopathy and confirmed recovery shortly after delivery [79]. Hence, COVID-19 infection during pregnancy may presage impending risk of serious complications and may explain the higher rate of caesarean sections during the third trimester of pregnancy to hasten delivery [8]. It is noteworthy to mention that the evidences link the prevalence and genetic risk 
factors of venous thromboembolism, vary significantly among different ethnic populations as low incidence of venous thromboembolism event was observed in Asian compared to Western population [83] [84] [85]. Recently, some published data pointed to the association of severe coronavirus disease 2019 (COVID-19) and complicated coagulopathy, DIC and the majority of deaths [57] [73] [78]. The ISTH has proposed a new category identifying an earlier phase of sepsis-associated DIC called "sepsis-induced coagulopathy" (SIC) [86], that will help to take decision for initiating anticoagulant therapy based on the diagnostic criteria of SIC [87]. COVID-19 infection during pregnancy increases the risk of pre-existent coagulopathy, hence any genuine complaint related to it should be considered especially those indicating pulmonary embolism.

In fact, chronic neutropenia which is relatively immunocompromised state that related to the COVID-19 course, is not a known cause of pregnancy associated coagulopathy [79]. This goes with the finding of a retrospective cohort study recruiting 38 pregnant women with chronic neutropenia syndromes, revealed no single case of coagulopathy was reported [88]. Hence, they extrapolated that the immunocompromised state causally related to the COVID-19 infection [79]. Likewise, COVID-19 infection is commonly associated with lymphopenia [89], elevated lactate dehydrogenase and higher levels of inflammatory markers (D-dimer, ferritin, C reactive protein, and interleukin-6 (IL-6)) [90]. Moreover, elevated IL-6 levels may predict disease severity, and correlate with a procoagulant profile [91]. Basically, the most consistent hemostatic abnormalities with COVID-19 infection are mild thrombocytopenia [82], and elevated D-dimer levels [92], which hire a higher risk of severe morbidity and increased fatality: increase rate of mechanical ventilation, intensive care unit admission, or death [81] [82]. Surprisingly, patients with severe pneumonia induced by SARS-CoV2 had higher platelet count than those induced by non-SARS-CoV2 infection, but only the former with significantly higher levels of D-dimer may gain benefit from anticoagulant therapy [57] [73] [78] [93]. This might indicate the severe inflammatory reaction and hypercoagulability among patients with COVID infection, and platelet count is not a sensitive marker for coagulopathy process related to COVID-19 disease [57] [73] [78] [93].

It is important to consider the side effects of some medications that are used for treating COVID-19 infection and have interactions with oral antiplatelet agents and increase risk of coagulopathy: Lopinavir/ritonavir is a protease inhibitor and inhibits CYP3A4 metabolism, ticagrelor inhibits CYP3A4 that potentiates its effects and remdesivir, a nucleotide-analog inhibitor of RNA-dependent RNA polymerase, is an inducer of CYP3A4 [80]. Clinically, incident venous thromboembolism was reported in $25 \%$ of severe COVID- 19 patients who required ICU admission in China [94], 30\% in the Netherlands [95], and 40\% diagnosed with pulmonary embolism based computed tomography angiography imaging [96]. Furthermore, a retrospective study from China, revealed 5\% incidence of stroke among hospitalized patients with COVID-19 [97]. Pregnancy, 
COVID-19 infection and some medications used during the course of the disease collectively increase the risk of susceptibility and severity of coagulopathy events. Hence vigilance is highly appreciated in managing COVID-19 during pregnancy.

\section{Limitation}

This study used only PubMed and Google scholar database and some valuable data are not included. Lack data assessing a large number of pregnant women as it is novel virus. Other risk factors like age, other comorbidities, maternal and perinatal are not covered here. Another limitation is related to the article selection criteria that were used.

\section{Conclusion}

Pregnancy, associated comorbidities and adaptive immune response are potential risk factors for contracting COVID-19 and predicting maternal and perinatal complications. Moreover, pregnancy and COVID-19 infection, directly and indirectly magnify the risk of coagulopathy, hence vigilant and proper management is warranted for such patients.

\section{Authors' Contributions}

IR designed the study, gathered and entered the data, drafted the manuscript, revised the manuscript and finalized it.

\section{Availability of Data and Materials}

The datasets used and/or analyzed during the current study are available from the database search engine.

\section{Consent for Publication}

Not applicable.

\section{Ethics Approval and Consent to Participate}

Not applicable.

\section{Conflicts of Interest}

The author declares no conflicts of interest regarding the publication of this paper.

\section{References}

[1] Worldometer (2020) Coronavirus Cases. Worldometer, 1-22. https://www.worldometers.info/coronavirus/coronavirus-cases/\#daily-cases

[2] CDC COVID-19 Response Team (2020) Preliminary Estimates of the Prevalence of Selected Underlying Health Conditions among Patients with Coronavirus Disease 2019-United States, February 12-March 28, 2020. Morbidity and Mortality Weekly 
Report (MMWR), 69, 382-386. https://doi.org/10.15585/mmwr.mm6913e2

[3] Chen, L., Li, Q., Zheng, D.N., et al. (2020) Clinical Characteristics of Pregnant Women with COVID-19 in Wuhan, China. The New England Journal of Medicine, 382, e100. https://doi.org/10.1056/NEJMc2009226

[4] Omar, S.M., Musa, I.R., Osman, O.E. and Adam, I. (2020) Prevalence and Associated Factors of Hypertension among Adults in Gadarif in Eastern Sudan: A Community-Based Study. BMC Public Health, 20, Article No. 291. https://doi.org/10.1186/s12889-020-8386-5

[5] Manus, M.B., Bloomfield, G.S., Leonard, A.S., Guidera, L.N., Samson, D.R. and Nunn, C.L. (2018) High Prevalence of Hypertension in an Agricultural Village in Madagascar. PLoS ONE, 13, e0201616. https://doi.org/10.1371/journal.pone.0201616

[6] Omar, S.M., Musa, I.R., Elsouli, A. and Adam, I. (2019) Prevalence, Risk Factors, and Glycaemic Control of Type 2 Diabetes Mellitus in Eastern Sudan: A Community-Based Study. Therapeutic Advances in Endocrinology and Metabolism, 10, 1-8. https://doi.org/10.1177/2042018819860071

[7] Robbiati, C., Putoto, G., Da Conceição, N., et al. (2020) Diabetes and Pre-Diabetes among Adults Reaching Health Centers in Luanda, Angola: Prevalence and Associated Factors. Scientific Reports, 10, Article No. 4565. https://doi.org/10.1038/s41598-020-61419-y

[8] Zaigham, M. and Andersson, O. (2020) Maternal and Perinatal Outcomes with COVID-19: A Systematic Review of 108 Pregnancies. Acta Obstetricia et Gynecologica Scandinavica, 99, 823-829. https://doi.org/10.1111/aogs.13867

[9] Verity, R., Okell, L.C., Dorigatti, I., et al. (2020) Estimates of the Severity of Coronavirus Disease 2019: A Model-Based Analysis. The Lancet Infectious Diseases, 20, 669-677. https://doi.org/10.1016/S1473-3099(20)30243-7

[10] Wang, C., Horby, P.W., Hayden, F.G. and Gao, G.F. (2020) A Novel Coronavirus Outbreak of Global Health Concern. The Lancet, 39, 470-473.

https://doi.org/10.1016/S0140-6736(20)30185-9

[11] Guan, W.J., Ni, Z.Y., Hu, Y., Liang, W.H., Ou, C.Q., He, J.X., et al. (2020) Clinical Characteristics of Coronavirus Disease 2019 in China. The New England Journal of Medicine, 382, 1708-1720. https://doi.org/10.1056/NEJMoa2002032

[12] Elshafeey, F., Magdi, R., Hindi, N., et al. (2020) A Systematic Scoping Review of COVID-19 during Pregnancy and Childbirth. International Journal of Gynecology \& Obstetrics, 150, 47-52. https://doi.org/10.1002/ijgo.13182

[13] WHO (2020) Middle East Respiratory Syndrome Coronavirus (MERS-CoV). WHO, Geneva. https://www.who.int/emergencies/mers-cov/en/

[14] Wong, S.F., Chow, K.M., Leung, T.N., et al. (2004) Pregnancy and Perinatal Outcomes of Women with Severe Acute Respiratory Syndrome. American Journal of Obstetrics \& Gynecology, 191, 292-297. https://doi.org/10.1016/j.ajog.2003.11.019

[15] Hantoushzadeh, S., Shamshirsaz, A.A., Aleyasin, A., et al. (2020) Maternal Death Due to COVID-19. American Journal of Obstetrics \& Gynecology, 223, 109.E1-109.E16. https://doi.org/10.1016/j.ajog.2020.04.030

[16] Moher, D., Liberati, A., Tetzlaff, J., Altman, D.G. and PRISMA Group (2009) Preferred Reporting Items for Systematic Reviews and Meta-Analyses: The PRISMA Statement. PLoS Medicine, 6, e1000097. https://doi.org/10.1371/journal.pmed.1000097

[17] Mcarthur, A., Klugárová, J., Yan, H. and Florescu, S. (2015) Innovations in the Sys- 
tematic Review of Text and Opinion. International Journal of Evidence-Based Healthcare, 13, 188-195. https://doi.org/10.1097/XEB.0000000000000060

[18] Rasmussen, S.A., Smulian, J.C., Lednicky, J.A., Wen, T.S. and Jamieson, D.J. (2020) Coronavirus Disease 2019 (COVID-19) and Pregnancy: What Obstetricians Need to Know. American Journal of Obstetrics \& Gynecology, 222, 415-426.

[19] Yang, H., Wang, C. and Poon, L.C. (2020) Novel Coronavirus Infection and Pregnancy. Ultrasound in Obstetrics \& Gynecology, 55, 435-437. https://doi.org/10.1002/uog.22006

[20] Liu, D.H., Li, L., Wu, X., Zheng, D.D., Wang, J.Z., Yang, L. and Zheng, C.S. (2020) Pregnancy and Perinatal Outcomes of Women with Coronavirus Disease (COVID-19) Pneumonia: A Preliminary Analysis. American Journal of Roentgenology, 215, 127-132. https://doi.org/10.2214/AJR.20.23072

[21] Dashraath, P., Wong, J.L.J., Lim, M.X.K., et al. (2020) Coronavirus Disease 2019 (COVID-19) Pandemic and Pregnancy. American Journal of Obstetrics \& Gynecology, 222, 521-531. https://doi.org/10.1016/j.ajog.2020.03.021

[22] Hughes, G.C., Clark, E.A. and Wong, A.H. (2013) The Intracellular Progesterone Receptor Regulates CD4 ${ }^{+} \mathrm{T}$ Cells and T Cell-Dependent Antibody Responses. Journal of Leukocyte Biology, 93, 369-375.

[23] Shah, N.M., Lai, P.F., Imami, N. and Johnson, M.R. (2019) Progesterone-Related Immune Modulation of Pregnancy and Labor. Frontiers in Endocrinology (Lausanne), 10, 198.

[24] Borba, V.V., Zandman-Goddard, G. and Shoenfeld, Y. (2018) Prolactin and Autoimmunity. Frontiers in Immunology, 9, 73.

https://doi.org/10.3389/fimmu.2018.00073

[25] Narang, K., Enninga, E.A.L., Gunaratne, M.D.S.K., et al. (2020) SARS-CoV-2 Infection and COVID-19 during Preg-Nancy: A Multidisciplinary Review. Mayo Clinic Proceedings, 95, 1750-1765. https://doi.org/10.1016/j.mayocp.2020.05.011

[26] Hanna, N., Hanna, M. and Sharma, S. (2020) Is Pregnancy an Immunological Contributor to Severe or Controlled COVID-19 Disease? American Journal of Reproductive Immunology, e13317. https://doi.org/10.1111/aji.13317

[27] Gardner, M.O. and Doyle, N.M. (2004) Asthma in Pregnancy. Obstetrics and Gynecology Clinics of North America, 31, 385-413. https://doi.org/10.1016/j.ogc.2004.03.010

[28] Jamieson, D.J., Honein, M.A., Rasmussen, S.A., Williams, J.L., Swerdlow, D.L., Biggerstaff, M.S., et al. (2009) H1N1 2009 Influenza Virus Infection during Pregnancy in the USA. The Lancet, 374, 451-458. https://doi.org/10.1016/S0140-6736(09)61304-0

[29] Chen, H., Guo, J., Wang, C., et al. (2020) Clinical Characteristics and Intrauterine Vertical Transmission Potential of COVID-19 Infection in Nine Pregnant Women: A Retrospective Review of Medical Records. The Lancet, 395, 809-815. https://doi.org/10.1016/S0140-6736(20)30360-3

[30] Qiao, J. (2020) What Are the Risks of COVID-19 Infection in Pregnant Women? The Lancet, 395, 760-762. https://doi.org/10.1016/S0140-6736(20)30365-2

[31] Mimouni, F., Lakshminrusimha, S., Pearlman, S.A., et al. (2020) Perinatal Aspects on the COVID-19 Pandemic: A Practical Resource for Perinatal-Neonatal Specialists. Journal of Perinatology, 40, 820-826. https://doi.org/10.1038/s41372-020-0665-6

[32] Li, B., Yang, J., Zhao, F.M., Zhi, L.L., Wang, X.Q., Liu, L., Bi, Z.H. and Zhao, Y.H. 
(2020) Prevalence and Impact of Cardiovascular Metabolic Diseases on COVID-19 in China. Clinical Research in Cardiology, 109, 531-538. https://doi.org/10.1007/s00392-020-01626-9

[33] Richardson, S., Hirsch, J.S., Narasimhan, M., et al. (2020) Presenting Characteristics, Comorbidities, and Outcomes among 5700 Patients Hospitalized with COVID-19 in the New York City Area. JAMA, 323, 2052-2059. https://doi.org/10.1001/jama.2020.6775

[34] Breslin, N., Baptiste, C., Gyamfi-Bannerman, C., et al. (2020) COVID-19 Infection among Asymptomatic and Symptomatic Pregnant Women: Two Weeks of Confirmed Presentations to an Affiliated Pair of New York City Hospitals. American Journal of Obstetrics \& Gynecology MFM, 2, Article ID: 100118. https://doi.org/10.1016/j.ajogmf.2020.100118

[35] Andersen, C.J., Murphy, K.E. and Fernandez, M.L. (2016) Impact of Obesity and Metabolic Syndrome on Immunity. Advances in Nutrition, 7, 66-75.

https://doi.org/10.3945/an.115.010207

[36] Ouchi, N., Parker, J.L., Lugus, J.J. and Walsh, K. (2011) Adipokines in Inflammation and Metabolic Disease. Nature Reviews Immunology, 11, 85-97. https://doi.org/10.1038/nri2921

[37] Zheng, Q., Cui, G., Chen, J., Gao, H., Wei, Y., Uede, T., Chen, Z. and Diao, H. (2015) Regular Exercise Enhances the Immune Response against Microbial Antigens through Up-Regulation of Toll-Like Receptor Signaling Pathways. Cellular Physiology and Biochemistry, 37, 735-746. https://doi.org/10.1159/000430391

[38] Reidy, P.T., Yonemura, N.M., Madsen, J.H., et al. (2019) An Accumulation of Muscle Macrophages Is Accompanied by Altered Insulin Sensitivity after Reduced Activity and Recovery. Acta Physiologica, 226, e13251. https://doi.org/10.1111/apha.13251

[39] Klinkhammer, J., Schnepf, D., Ye, L., et al. (2018) IFN- $\lambda$ Prevents Influenza Virus Spread from the Upper Airways to the Lungs and Limits Virus Transmission. eLife, 7, e33354. https://doi.org/10.7554/eLife.33354.018

[40] Honce, R., Karlsson, E.A., Wohlgemuth, N., Estrada, L.D., Meliopoulos, V.A., Yao, J. and Schultz-Cherry, S. (2020) Obesity-Related Microenvironment Promotes Emergence of Virulent Influenza Virus Strains. mBio, 11, e03341-19. https://doi.org/10.1128/mBio.03341-19

[41] Corne, J.M., Marshall, C., Smith, S., et al. (2002) Frequency, Severity, and Duration of Rhinovirus Infections in Asthmatic and Non-Asthmatic Individuals: A Longitudinal Cohort Study. The Lancet, 359, 831-834. https://doi.org/10.1016/S0140-6736(02)07953-9

[42] Jackson, D.J., Trujillo-Torralbo, M.B., Del-Rosario, J., et al. (2015) The Influence of Asthma Control on the Severity of Virus-Induced Asthma Exacerbations. Journal of Allergy and Clinical Immunology, 136, 497-500.e3. https://doi.org/10.1016/j.jaci.2015.01.028

[43] Sykes, A., Edwards, M.R., Macintyre, J., et al. (2012) Rhinovirus 16-Induced IFN- $\alpha$ and IFN- $\beta$ Are Deficient in Bronchoalveolar Lavage Cells in Asthmatic Patients. Journal of Allergy and Clinical Immunology, 129, 1506-1514.e6. https://doi.org/10.1016/j.jaci.2012.03.044

[44] Wark, P.A., Johnston, S.L., Bucchieri, F., et al. (2005) Asthmatic Bronchial Epithelial Cells Have a Deficient Innate Immune Response to Infection with Rhinovirus. Journal of Experimental Medicine, 201, 937-947. https://doi.org/10.1084/jem.20041901 
[45] Contoli, M., Message, S.D., Laza-Stanca, V., et al. (2006) Role of Deficient Type III Interferon-Lambda Production in Asthma Exacerbations. Nature Medicine, 12, 1023-1026. https://doi.org/10.1038/nm1462

[46] Epidemiology Working Group for NCIP Epidemic Response, Chinese Center for Disease Control and Prevention (2020) The Epidemiological Characteristics of an Outbreak of 2019 Novel Coronavirus Diseases (COVID-19) in China. Zhonghua Liu Xing Bing Xue Za Zhi, 41, 145-151.

[47] Yang, X.B., Yu, Y., Xu, J.Q., et al. (2020) Clinical Course and Outcomes of Critically Ill Patients with SARS-CoV-2 Pneumonia in Wuhan, China: A Single-Centered, Retrospective, Observational Study. The Lancet Respiratory Medicine, 8, 475-481.

[48] Musa, I.R. (2020) Risk Factors Associated with COVID-19 Infection among Patients with Diabetes Mellitus. Diabetes \& Its Complications, 4, 1-8.

http://www.scivisionpub.com/pdfs/risk-factors-associated-with-COVID19-infection -among-patients-with-diabetes-mellitus-1165.pdf

[49] Zhang, J.J., Dong, X., Cao, Y.Y., et al. (2020) Clinical Characteristics of 140 Patients Infected with SARS-CoV-2 in Wuhan, China. Allergy, 75, 1730-1741.

https://doi.org/10.1111/all.14238

[50] Gidlöf, S., Savchenko, J., Brune, T. and Josefsson, H. (2020) COVID-19 in Pregnancy with Comorbidities: More Liberal Testing Strategy Is Needed. Acta Obstetricia et Gynecologica Scandinavica, 99, 948-949. https://doi.org/10.1111/aogs.13862

[51] Zhao, Y., Zhao, Z.X., Wang, Y.J., Zhou, Y.Q., Ma, Y. and Zuo, W. (2020) Single-Cell RNA Expression Profiling of ACE2, the Receptor of SARS-CoV-2. American Journal of Respiratory and Critical Care Medicine, 202, 756-759.

http://www.ncbi.nlm.nih.gov/pubmed/32663409

[52] Mathad, J.S. and Gupta, A. (2017) Pulmonary Infections in Pregnancy. Seminars in Respiratory and Critical Care Medicine, 38, 174-184. https://doi.org/10.1055/s-0037-1602375

[53] Liu, H., Wang, L.L., Zhao, S.J., Kwak-Kim, J., Mor, G. and Liao, A.H. (2020) Why Are Pregnant Women Susceptible to COVID-19? An Immunological Viewpoint. Journal of Reproductive Immunology, 139, Article ID: 103122. https://doi.org/10.1016/j.jri.2020.103122

[54] Berger, A. (2000) Th1 and Th2 Responses: What Are They? BMJ, 321, 424. https://doi.org/10.1136/bmj.321.7258.424

[55] Wu, J.T., Leung, K. and Leung, G.M. (2020) Nowcasting and Forecasting the Potential Domestic and International Spread of the 2019-nCoV Outbreak Originating in Wuhan, China: A Modelling Study. The Lancet, 395, 689-697. https://doi.org/10.1016/S0140-6736(20)30260-9

[56] Wong, C.K., Lam, C.W., Wu, A.K., et al. (2004) Plasma Inflammatory Cytokines and Chemokines in Severe Acute Respiratory Syndrome. Clinical \& Experimental Immunology, 136, 95-103. https://doi.org/10.1111/j.1365-2249.2004.02415.x

[57] Huang, C.L., Wang, Y.M., Li, X.W., Ren, L.L., Zhao, J.P., Hu, Y., et al. (2020) Clinical Features of Patients Infected with 2019 Novel Coronavirus in Wuhan, China. The Lancet, 395, 497-506. https://doi.org/10.1016/S0140-6736(20)30183-5

[58] Ruan, Q.R., Yang, K., Wang, W.X., Jiang, L.Y. and Song, J.X. (2020) Clinical Predictors of Mortality Due to COVID-19 Based on an Analysis of Data of 150 Patients from Wuhan, China. Intensive Care Medicine, 46, 846-848.

https://doi.org/10.1007/s00134-020-05991-X

[59] Littauer, E.Q., Esser, E.S., Antao, O.Q., Vassilieva, E.V., Compans, R.W. and Skountzou, I. (2017) H1N1 Influenza Virus Infection Results in Adverse Pregnancy 
Outcomes by Disrupting Tissue-Specific Hormonal Regulation. PLoS Pathogens, 13, e1006757. https://doi.org/10.1371/journal.ppat.1006757

[60] Thevarajan, I., Nguyen, T.H.O., Koutsakos, M., et al. (2020) Breadth of Concomitant Immune Responses Prior to Patient Recovery: A Case Report of Non-Severe COVID-19. Nature Medicine, 26, 453-455. https://doi.org/10.1038/s41591-020-0819-2

[61] Szarka, A., Rigó Jr., J., Lázár, L., Beko, G. and Molvarec, A. (2010) Circulating Cytokines, Chemokines and Adhesion Molecules in Normal Pregnancy and Preeclampsia Determined by Multiplex Suspension Array. BMC Immunology, 11, Article No. 59. https://doi.org/10.1186/1471-2172-11-59

[62] Aghaeepour, N., Ganio, E.A., Mcilwain, D., et al. (2017) An Immune Clock of Human Pregnancy. Science Immunology, 2, Eaan2946.

https://doi.org/10.1126/sciimmunol.aan2946

[63] Tetro, J.A. (2020) Is COVID-19 Receiving ADE from Other Coronaviruses? Microbes and Infection, 22, 72-73. https://doi.org/10.1016/j.micinf.2020.02.006

[64] Mor, G., Aldo, P. and Alvero, A.B. (2017) The Unique Immunological and Microbial Aspects of Pregnancy. Nature Reviews Immunology, 17, 469-482.

https://doi.org/10.1038/nri.2017.64

[65] Mor, G. and Cardenas, I. (2010) The Immune System in Pregnancy: A Unique Complexity. American Journal of Reproductive Immunology, 63, 425-433. https://doi.org/10.1111/j.1600-0897.2010.00836.x

[66] Abbassi-Ghanavati, M., Greer, L.G. and Cunningham, F.G. (2009) Pregnancy and Laboratory Studies: A Reference Table for Clinicians. Obstetrics \& Gynecology, 114, 1326-1331. https://doi.org/10.1097/AOG.0b013e3181c2bde8

[67] Levi, M. and Van der Poll, T. (2017) Coagulation and Sepsis. Thrombosis Research, 149, 38-44. https://doi.org/10.1016/j.thromres.2016.11.007

[68] Schmitt, F.C.F., Manolov, V., Morgenstern, J., et al. (2019) Acute Fibrinolysis Shutdown Occurs Early in Septic Shock and Is Associated with Increased Morbidity and Mortality: Results of an Observational Pilot Study. Annals of Intensive Care, 9, Article No. 19. https://doi.org/10.1186/s13613-019-0499-6

[69] Fung, S.Y., Yuen, K.S., Ye, Z.W., Chan, C.P. and Jin, D.Y. (2020) A Tug-of-War between Severe Acute Respiratory Syndrome Coronavirus 2 and Host Antiviral Defence: Lessons from Other Pathogenic Viruses. Emerging Microbes \& Infections, 9 , 558-570. https://doi.org/10.1080/22221751.2020.1736644

[70] Schultz, M.J. and Spronk, P.E. (2006) Hypothermia and Lung Rest for Acute Lung Injury: Truly Exploiting Reduced Ventilatory Need or Just the Treatment Benefit of Hypothermia Alone? Critical Care Medicine, 34, 936.

https://doi.org/10.1097/01.CCM.0000202136.91651.34

[71] Varga, Z., Flammer, A.J., Steiger, P., et al. (2020) Endothelial Cell Infection and Endotheliitis in COVID-19. The Lancet, 395, 1417-1418. https://doi.org/10.1016/S0140-6736(20)30937-5

[72] Gupta, N., Zhao, Y.Y. and Evans, C.E. (2019) The Stimulation of Thrombosis by Hypoxia. Thrombosis Research, 181, 77-83. https://doi.org/10.1016/j.thromres.2019.07.013

[73] Tang, N., Li, D.J., Wang, X. and Sun, Z.Y. (2020) Abnormal Coagulation Parameters Are Associated with Poor Prognosis in Patients with Novel Coronavirus Pneumonia. Journal of Thrombosis and Haemostasis, 18, 844-847.

https://doi.org/10.1111/jth.14768 
[74] Fan, B.E., Chong, V.C.L., Chan, S.S.W., et al. (2020) Hematologic Parameters in Patients with COVID-19 Infection. American Journal of Hematology, 95, E131-E134. https://doi.org/10.1002/ajh.25847

[75] Luo, W.R., Yu, H., Gou, J.Z., Li, X.X., Sun, Y., Li, J.X. and Liu, L. (2020) Clinical Pathology of Critical Patient with Novel Coronavirus Pneumonia (COVID-19). Preprints 2020, 2020020407. https://www.preprints.org/manuscript/202002.0407/v2

[76] Tang, N., Bai, H., Chen, X., Gong, J.L., Li, D.J. and Sun, Z.Y. (2020) Anticoagulant Treatment Is Associated with Decreased Mortality in Severe Coronavirus Disease 2019 Patients with Coagulopathy. Journal of Thrombosis and Haemostasis, 18, 1094-1099. https://doi.org/10.1111/jth.14817

[77] Thachil, J., Tang, N., Gando, S., et al. (2020) ISTH Interim Guidance on Recognition and Management of Coagulopathy in COVID-19. Journal of Thrombosis and Haemostasis, 18, 1023-1026. https://doi.org/10.1111/jth.14810

[78] Chen, N.S., Zhou, M., Dong, X., Qu, J.M., Gong, F.Y., Han, Y., et al. (2020) Epidemiological and Clinical Characteristics of 99 Cases of 2019 Novel Coronavirus Pneumonia in Wuhan, China: A Descriptive Study. The Lancet, 395, 507-513. https://doi.org/10.1016/S0140-6736(20)30211-7

[79] Koumoutsea, E.V., Vivanti, A.J., Shehata, N., et al. (2020) COVID-19 and Acute Coagulopathy in Pregnancy. Journal of Thrombosis and Haemostasis, 18, 1648-1652. https://doi.org/10.1111/jth.14856

[80] Bikdeli, B., Madhavan, M.V., Jimenez, D., et al. (2020) COVID-19 and Thrombotic or Thromboembolic Disease: Implications for Prevention, Antithrombotic Therapy, and Follow-Up: JACC State-of-the-Art Review. Journal of the American College of Cardiology, 75, 2950-2973. https://doi.org/10.1016/j.jacc.2020.04.031

[81] Han, H., Yang, L., Liu, R., et al. (2020) Prominent Changes in Blood Coagulation of Patients with SARS-CoV-2 Infection. Clinical Chemistry and Laboratory Medicine, 58, 1116-1120. https://doi.org/10.1515/cclm-2020-0188

[82] Lippi, G. and Plebani, M. (2020) Laboratory Abnormalities in Patients with COVID-2019 Infection. Clinical Chemistry and Laboratory Medicine, 58, 1131-1134. https://doi.org/10.1515/cclm-2020-0198

[83] Hong, J., Lee, J.H., Yhim, H. Y., Choi, W.I., Bang, S.M., Lee, H. and Oh, D. (2018) Incidence of Venous Thromboembolism in Korea from 2009 to 2013. PLoS ONE, 13, e0191897. https://doi.org/10.1371/journal.pone.0191897

[84] Zakai, N.A. and Mcclure, L.A. (2011) Racial Differences in Venous Thromboembolism. Journal of Thrombosis and Haemostasis, 9, 1877-1882. https://doi.org/10.1111/j.1538-7836.2011.04443.x

[85] Stein, P.D., Kayali, F., Olson, R.E. and Milford, C.E. (2004) Pulmonary Thromboembolism in Asians/Pacific Islanders in the United States: Analysis of Data from the National Hospital Discharge Survey and the United States Bureau of the Census. The American Journal of Medicine, 116, 435-442. https://doi.org/10.1016/j.amjmed.2003.11.020

[86] Iba, T., Levy, J.H., Warkentin, T.E., et al. (2019) Diagnosis and Management of Sepsis-Induced Coagulopathy and Disseminated Intravascular Coagulation. Journal of Thrombosis and Haemostasis, 17, 1989-1994. https://doi.org/10.1111/jth.14578

[87] Iba, T., Nisio, M.D., Levy, J.H., et al. (2017) New Criteria for Sepsis-Induced Coagulopathy (SIC) Following the Revised Sepsis Definition: A Retrospective Analysis of a Nationwide Survey.BMJ Open, 7, e017046. https://doi.org/10.1136/bmjopen-2017-017046

[88] Zeidler, C., Grote, U.A., Nickel, A., et al. (2014) Outcome and Management of 
Pregnancies in Severe Chronic Neutropenia Patients by the European Branch of the Severe Chronic Neutropenia International Registry. Haematologica, 99, 1395-1402. https://doi.org/10.3324/haematol.2013.099101

[89] Zhou, P., Yang, X.L., Wang, X.G., et al. (2020) A Pneumonia Outbreak Associated with a New Coronavirus of Probable Bat Origin. Nature, 579, 270-273. https://doi.org/10.1038/s41586-020-2012-7

[90] Zhou, F., Yu, T., Du, R.H., Fan, G.H., Liu, Y., Liu, Z.B., et al. (2020) Articles Clinical Course and Risk Factors for Mortality of Adult Inpatients with COVID-19 in Wuhan, China: A Retrospective Cohort Study. The Lancet, 395, 1054-1062.

[91] Libby, P. and Simon, D.I. (2001) Inflammation and Thrombosis: The Clot Thickens. Circulation, 103, 1718-1720. https://doi.org/10.1161/01.CIR.103.13.1718

[92] Lippi, G. and Favaloro, E.J. (2020) D-Dimer Is Associated with Severity of Coronavirus Disease 2019: A Pooled Analysis. Thrombosis and Haemostasis, 120, 876-878. https://doi.org/10.1055/s-0040-1709650

[93] Yin, S.Y., Huang, M., Li, D.J. and Tang, N. (2020) Difference of Coagulation Features between Severe Pneumonia Induced by SARS-CoV2 and Non-SARS-CoV2. Journal of Thrombosis and Thrombolysis. https://doi.org/10.1007/s11239-020-02105-8

[94] Cui, S.P., Chen, S., Li, X.N., Liu, S. and Wang, F. (2020) Prevalence of Venous Thromboembolism in Patients with Severe Novel Coronavirus Pneumonia. Journal of Thrombosis and Haemostasis, 18, 1421-1424. https://doi.org/10.1111/jth.14830

[95] Klok, F.A., Kruip, M.J.H.A., Van Der Meer, N.J.M., Arbous, M.S., Gommers, D.A.M.P.J., Kant, K.M., et al. (2020) Incidence of Thrombotic Complications in Critically Ill ICU Patients with COVID-19. Thrombosis Research, 191, 145-147. https://doi.org/10.1016/j.thromres.2020.04.013

[96] Wang, T., Chen, R.C., Liu, C.L., Liang, W.H., Guan, W.J., Tang, R.D., et al. (2020) Attention Should Be Paid to Venous Thromboembolism Prophylaxis in the Management of COVID-19. The Lancet Haematology, 7, E362-E363. https://doi.org/10.1016/S2352-3026(20)30109-5

[97] Li, Y., Li, M., Wang, M.D., et al. (2020) Acute Cerebrovascular Disease Following COVID-19: A Single Center, Retrospective, Observational Study. Stroke \& Vascular Neurology. https://doi.org/10.1136/svn-2020-000431 


\section{Abbreviations}

COVID-19: Coronavirus Disease 2019.

SARS-CoV: Severe Acute Respiratory Syndrome Coronavirus. MERS-CoV: Middle East Respiratory Syndrome Coronavirus. DM: Diabetes Mellitus.

ICU: Intensive Care Unit.

IFN- $\gamma$. Interferon Gamma.

TNF- $\alpha$ : Tumor Necrosis Factor Alpha.

IL: Interleukin.

$\mathrm{CD}^{+} \mathrm{T}$ cells: $\mathrm{CD}^{+}$(Cytotoxic) T cells.

Th1: T helper cell type 1 .

Th2: T helper cell type 2 .

ISTH: International Society on Thrombosis and Haemostasis.

DIC: Disseminated Intravascular Coagulopathy.

SIC: Sepsis Induced Coagulopathy. 